\title{
Re-working mobilities: Emergent geographies of employment-related mobility
}

\section{Sara Dorow ${ }^{1}$ (D) | Sharon R. Roseman ${ }^{2}$ | Tim Cresswell ${ }^{3}$}

\author{
${ }^{1}$ Sociology, University of Alberta \\ ${ }^{2}$ Anthropology, Memorial University \\ ${ }^{3}$ American Studies, Trinity College \\ Correspondence \\ Sara Dorow, Sociology, University of Alberta, \\ Alberta, Canada. \\ Email: sdorow@ualberta.ca \\ Funding information \\ Social Sciences and Humanities Research \\ Council, Grant/Award Number: Appl ID \\ 895-2011-1019
}

\begin{abstract}
Over the last decade, an increasing number of geographers and other social science researchers have deployed the insights of the new mobilities paradigm to study work, labour, and employment. These insights include attention to the meanings, practices, and politics of work-related movement as well as to multiple spatial and temporal scales and types of im/mobility for and at work. In a review of this literature, we find five different vantage points on "re-working" mobility: articulations of labour migration with other forms of mobility; geometries of power in the daily journey to work; embodiment and affect in work-related movement; mobility and labour across the life course; and co-mobilities of workers, ideas, and things. We argue that on whole, a mobility lens offers a "critical phenomenology" of the dynamic relations between the everyday lifeworlds and broader political, social, and economic contexts of both paid and unpaid work. This is especially important as work involves ever more complex patterns and experiences of mobility and is more deeply entwined with the mobilities of other domains of social life. We conclude by considering the rich implications of "re-working mobilities" for methodological diversity and for animating both mobilities studies and labour studies as critical geographical endeavors.
\end{abstract}

\section{1 | INTRODUCTION}

Geographers have long examined the spatio-temporal organisation and experience of work, workplaces, and working lives, and have explored the centrality to these of relationships and movements between different places. As work and

The co-authors are part of the On the Move Partnership: Employment-Related Geographical Mobility in the Canadian Context, a project of the SafetyNet Centre for Occupational Health \& Safety Research at Memorial University. On the Move is supported by the Social Sciences and Humanities Research Council through its Partnership Grants funding opportunity (Appl ID 895-2011-1019), the Research \& Development Corporation of Newfoundland and Labrador, the Canada Foundation for Innovation, and numerous university and community partners in Canada and elsewhere. 
employment become more geographically complex, it is all the more important to pay attention to these interconnections. Employment demands intricate patterns of movement and circulation across multiple places and scales (Cresswell, Dorow, \& Roseman, 2016), is simultaneously stretched out across national lines and intensified in the local (Massey, 1994), entails proliferating forms of digital communication and virtual work (Green, 2002), increasingly involves nonstandard, flexibilised, and precarious work schedules (Hinrichs, Roche, \& Sirianni, 1991; Waite, 2009), and blurs lines between the places and times of paid work and other aspects of life (Weeks, 2007).

This is a dizzying list. And while there is no conceptual panacea for tackling such complexities, the new mobilities paradigm (NMP) provides one generative conceptual apparatus for doing so. This is not just because mobilities of all kinds are an increasingly important characteristic or even agent of the organisation and experience of work life but also because this paradigm offers a rich conceptual lens on work. In our review of recent literature that applies a mobility lens to the study of work and work-related phenomena-especially but not exclusively within geography or the NMP-we find that it offers a kind of "critical phenomenology" (Desjarlais, 2005) of the geography of work: it illuminates the spatial and temporal connections between everyday lifeworlds of work and "interrelated social, discursive, and political forces" (p. 369) that condition and are conditioned by those lifeworlds. In other words, starting with mobility as the thing to be understood (rather than merely "as a constituent of larger social processes"; Faulconbridge \& Hui, 2016, p. 3) helps us to build a geography of work and employment as lived in context and as experienced in increasingly complex spatio-temporal arrangements interlaced with changing forms of power and inequality (Hislop \& Axtell, 2007; Kelly, 2012). This is what we dub re-working mobilities.

The new mobilities paradigm (sometimes called the new mobility studies or the mobility turn) asserts that while people have always been "on the move," what is different about the late 20th and early 21st centuries is the centrality of mobilities of all kinds and scales to political, economic, and social life (Cresswell, 2006; Hannam, Sheller, \& Urry, 2006). John Urry (2007), a sociologist and one of the key figures in the development of the NMP, went so far as to posit that mobility now defines what we take to be "the social" (see also Adey, 2010; Faulconbridge \& Hui, 2016). While mobility research was by no means new to geography, what Urry and colleagues in geography and sociology kickstarted just over a decade ago was a revised way of comprehending and "curating" research on mobility (Faulconbridge \& Hui, 2016, p. 3). Now a key term in geography ${ }^{1}$, the interdisciplinary mobilities field is wide and diverse. At its core is an interest in different kinds of movement (of people, but also of ideas, capital, things, etc.) across multiple spatial and temporal scales (from everyday micro-geographies to transnational circuits) and along spectra of proximity and distance (Adey, 2010) as well as rhythm, duration, and cycle (Crang, 2001; Law, 1999). It is a field attuned to how any one mobility inevitably implicates other scales and types of mobility, including forms of immobility, mooring, or stillness (Sheller \& Urry, 2006; Bissell, 2016). For mobility scholars, movement and stillness are only as interesting as the meanings (representations, metaphors, and discourses) with which they are entangled, the practices of individual and collective movement in which they are lived and embodied, and the politics of inequality, difference, control, and agency in which they are embroiled (Adey, 2010; Cresswell, 2010).

NMP research has emphasised the connections between embodied movement and "broader processes and problems" and "has highlighted how heterogenerous mobilities reproduce systems of governance and politics, as well as situated experiences and engagement" (Faulconbridge \& Hui, 2016, p. 5). A mobility lens is thus adept at capturing the dynamic and multi-faceted relationality between workers' experiences and lives, on the one hand, and sociogeographical structures, institutions, and conditions of work, on the other (see Herod, 1997; Kelly, 2012; Waite, 2009). Put another way, mobilities are both an agent of economic, political, and social relations of work and integral

\footnotetext{
${ }^{1}$ The codification of the NMP in the last decade is signaled by the development of the journals Mobilities, Transfers, and Applied Mobilities alongside a growing number of book collections, journal issues, conferences, and handbooks (Adey, Bissell, Hannam, Merriman, \& Sheller, 2014; Salazar \& Jayaram, 2016). However, a search of the journal Mobilities reveals that less than $10 \%$ of articles between 2006 and 2016 (26 of nearly 300 articles) are formally tagged with the subject term "labour" or "work". The two entries on "Mobility" by David Ley (Part I) and George Revill (Part II) in The Wiley-Blackwell Companion to Human Geography (2011) do not cover work or labour in any concerted way, although The Wiley-Blackwell Companion to Economic Geography (2012) includes an entry "Labor, movement: Migration, mobility, and geographies of work" by Philip Kelly.
} 
to lived human working activity. As a dynamic connective tissue between conditions and lifeworlds, mobilities provide a nuanced lens on complex contemporary geographies of work, including as they overlap with nonwork sites and practices.

The dynamics linking lived mobilities of work to conditioning processes are, of course, context-specific and contingent. One of the strengths of the NMP has been to insist on critical investigation of the specificities of particular cases or sites (Faulconbridge \& Hui, 2016). Research on work-related mobility might focus on a particular workplace, industry, route, community, or individual worker's life. Whatever the case, a mobility lens has the potential to reveal the circuits and nodes of power that reproduce and/or disrupt the spatio-temporal relations of work in any given context.

Consider several illustrative examples: the daily rhythms and circuits of hurried, hungry automobile commuters in the take-out queue combine with the physical and human infrastructure of the fast food franchise to shape the disciplined embodied movements and rhythms of fast food workers, many of whom might be immigrants or temporary migrant workers; the long-distance mobile circuits of masculine mining work are enabled by "moored" feminised care work carried out in the paid and unpaid work of the mining camp and the home, respectively; and a market-driven commodity chain of mobilities links the transport of parts to the daily micro-movements on the factory floor to the circulation of consumer products to the perambulations of the clerk on the retail floor.

Current approaches to these interrelationships have important historical roots in geography. Migration researchers, for example, have long linked work and mobility across multiple scales, more recently insisting that experiences of labour-related migration cannot be spatially siloed into inter-national and intra-national movement, let alone temporally siloed into short- and long-term migration (Ackers, 2005; Cohen, 2010; Jeanes, Loacker, Śliwa, \& Weiskopf, 2015). Critical feminist geography is also an important precursor, given its longstanding examinations of the relationship between inequalities of paid and unpaid work and raced, classed, and gendered differentiations in movement at everything from daily to transnational scales (Hanson \& Pratt, 1995; Law, 1999; McDowell, 2009; see also Yeoh \& Ramdas, 2014). Both of these literatures lay the groundwork for breaking down overwrought distinctions between mobility research and migration studies, as well as between local and transnational "levels" of analysis, in the study of work.

Building on this groundwork, a rich current of geographical literature is deploying a mobility lens to study the dynamic relationalities among human movement at multiple scales, on the one hand, and paid and unpaid labour, on the other. ${ }^{2}$ This research connects everyday meanings and practices of work to structural and cultural politics, builds understanding of these connections through careful attention to the contingencies of context, and foregrounds work and employment as translocal, multi-scalar, cross-temporal, and integrally bound up with other central social phenomena such as identity, family, and leisure (as themselves mobility-infused). In what follows, we present five different arenas of recent scholarship that while by no means exhaustive or discrete from each other, suggest a variety of vantage points from which geographers and select other social science researchers are contributing to "re-working mobilities" in these ways.

\section{I DYNAMIC RELATIONALITIES OF WORK AND MOBILITY: FIVE OVERLAPPING VANTAGE POINTS}

\section{1 | Labour migration amidst multiple mobilities}

We begin with a line of enquiry that treats labour migration as just one scale and type of mobility among many and furthermore, as inseparably articulated to these other scales and forms (see Hui, 2016; Blunt, 2007). Research in this vein illuminates the interplay between formal migration schemes and the creation and differentiation of workers' identities, and implicates translocal geographies of family, home, and community in lived experiences of work-related mobility.

${ }^{2}$ We and our colleagues are considering these conjunctions along a spectrum of what we call employment-related geographical mobility (Cresswell et al., 2016; Roseman, Barber, \& Neis, 2015). 
While not explicitly in conversation with the NMP, the team of Batnitzky, Dyer, and McDowell exemplifies some of the strengths of linking migration to mobilities. Their comparative examination of mobility pathways (e.g., of both housekeepers and front desk workers) within the London hotel industry's global workforce reveals racialised and gendered differentiations among workers to be a co-creation of the UK migration regime and workplace-based practices (Dyer, McDowell, \& Batnitzky, 2010). This includes the making of mobile identities. The "middle class global mobility" of Indian men in the hotel industry, for example, arises from a distinctive combination of Indian masculinities -including previous attachments to leisure travel and international migration as markers of status in India-with the gendered and classed recruitment practices of the hospitality industry in the UK (Batnitzky, McDowell, \& Dyer, 2008). Beck's (2007) comparative study of two Chinese ethnic groups in Liverpool also demonstrates how distinct migrant pathways play out in practices and identities of work-related im/mobility. Having come to Britain under a more commoditised and irregular (illegal) migration regime than that of earlier Cantonese migrants, Fujianese workers experience constant labour mobility and precarity. Their self-understanding as "sojourners" in the UK labour market is inseparable from the conditions under which they migrated and under which they continue to be surveilled by the Immigration Service.

Blurring the lines between labour migration and other forms and scales of mobility provides rich insights into intersectional identities and inequalities as an integrated feature of translocal work. One striking example comes from Silva and Ornat's (2015) multi-sited study of Brazilian travestis doing sex work in Spain. By attending to the multiple, intersecting mobilities of travesti work-illegal transnational migration, intense travel between cities in Spain to ensure "novelty" for clients, and the unpredictable daily movement among street or club locations where truques (tricks) occur -the authors make visible the spatio-temporal dynamics within which travestis fluidly create identities.

Other research addresses how mobile work subjectivities, including "mobile masculinities" (Datta et al., 2008), cross not just different scales but also different social sites of belonging such as home and community. In her examination of home-making practices and attachments among British expatriate men in Dubai, Walsh (2011) finds lines of connection between the micro-geographies of domestic practice and the masculinities of migrant work. She shows how home-based im/mobilising practices-placing "migrant souvenirs" from travel adventures in the home or gardening as a form of emplacement amidst uprootedness-expand the notion of the male migrant as working provider. Siri Gerrard's (2013) research situates interconnected forms of mobile work in the life of one Norwegian fisher family, from routinised regional labour migration to the daily journey out to the fishing grounds, within a network of technologies, gender ideologies, and fishery policies. With migration enfolded into multiple modes and practices of mobility, we see at once the intertwined structures and lifeworlds of fishing. In a similar vein but quite a different context, Verne (2012) captures the translocal trade relations of human and nonhuman mobilities spanning Tanzania, Dubai, London, and Toronto that make for fluidly constructed Swahili identities.

\section{2 | The mobile power-geometries of the "daily journey"}

At the other end of the scale from transnational migration, familiar acts of daily commuting offer a distinct vantage point for understanding the entanglements of mobilities with broader power-geometries. Pioneering research that unpacked the "geographies of employment" entailed in journeys-to-work (e.g., Hanson \& Pratt, 1995, pp. 93-119) directed us to appreciate how "daily mobility" sits at the junctures of race, class, and gender, connecting politics to practices and mediating employment and other aspects of life (Hanson, 2010; Law, 1999; Massey, 1993). Gilbert (1998), for example, found that, compared to white women, the daily activity patterns of African American women in Worcester, Massachusetts drew on "rootedness" or "place-based networks" to find employment and childcare (p. 614). This and parallel case studies of daily movements in context emphasise "how mobility and immobility are related to historically and geographically situated constellations of power relations" (Gilbert, 1998, p. 616; see also Hanson, 2005), including forms of resistance and agency (Hyndman, 2004; Law, 1999).

Recent research on distributions of mobility as a kind of "motility capital" is relevant for geographical and other studies of daily commuting (e.g., Kaufmann, Bergman, \& Joye, 2004; also Urry, 2007); in particular, it provides an 
intersectional lens on the webs of mobility connecting household dynamics and broader systems of work. Akyelken (2013) argues that women's ability to travel daily to jobs or job training in Mardin, Turkey is constrained by "power relations within the household" (p. 432) related to normative gender and kinship roles, which can supersede the impact of improved commuting infrastructure. This examination of the micro-geographies of constraint sits alongside research that demonstrates the converse: individual deployment of agency in the face of dominant power-geometries. Van Blerk (2016) discusses the choice by young, otherwise disempowered female sex workers in Ethiopia to purposefully live outside the "red-light areas" where they work, the "freedom" of their daily commute contrasting with long periods spent in "the micro-space of the room" (van Blerk, 2016, p. 418; see also Ritterbusch, 2016).

Transport infrastructures of the daily commute can be a focus for-as well as a place to stage-political mobilizations. Parks has reframed "the journey to work as a racial mobility project" (Parks, 2016, p. 292). She notes that "Commuting sits at the nexus of three primary urban racial projects: labor markets, housing, and transportation" (p. 293). By tying mobility studies to literature on "racial projects" (Omi \& Winant, 1994), she shows how Rosa Parks' refusal to move from her seat on her bus journey home from work in Montgomery, Alabama in 1955 is linked to later fights for "commuting equity" or "transit justice" in the United States and elsewhere (Parks, 2016, p. 297; see also Cresswell, 2006).

A critical phenomenological lens also allows for comparisons of the embodied and affective dimensions of journeys-to-work for differentially situated workers. These range from the gentle swaying and pleasing hums associated with privileged commuting to the frictions of physical discomfort and danger for low-income commuters (e.g., Edensor, 2011). Bissell's research has deepened our understanding of affect, practice, politics, and mediations in the daily journey. In a recent article, a subtle vignette of an Australian commuter train journey maps the intersection between the macro scale of inequalities organised by class, ethnicity, and gender and the "micropolitics of mobility ... that take place through events and encounters on the move" (Bissell, 2016, p. 395). Such analyses give specificity to the dynamic inequalities linking lifeworld and context.

\subsection{Embodied and affective mobilities at work}

A related arena of enquiry starts with bodily mobilities. Critical mobilities scholarship has drawn our attention to the everyday dynamics of working mobilities with a focus on emotions and the senses on the one hand and the dynamics of control and discipline on the other. Mitchell's (2012) examination of the impact of contemporary capitalism on the labouring bodies of immigrant farm workers in California, for example, has produced a discussion of embodied labour in the fields that reminds us of earlier research into the impacts of Taylorism in factories. Recent research translates questions of workplace discipline into the present day by taking into account the impact of digital surveillance technology in workplaces and in the world of logistics on the movements of working bodies (Kanngieser, 2013).

Ethnographic research has sought to uncover a phenomenology of working body-subjects. Examples include studies of bodily comportment and motion in the airline and trucking industries, where work and mobility are most intimately related (Lin, 2015; Nóvoa, 2014; Whitelegg, 2007). Lin (2015), for instance, examines the production of "affective atmospheres," and in particular, the production of the "Singapore girl," in the cabins of Singapore Airlines aircraft. He charts the "(more) minute and material practices that companies undertake to prepare bodies and other artefacts to relate to, placate and stir the emotions of customers" (p. 289). The micro-mobilities of the attendants as labour are finely tuned to service the macro-mobilities of the customers flying in and out of Singapore's global hub. In a similar vein, McMorran (2015) considers how forms of mobility and fixity are enacted in traditional Japanese inns. The inns are places for globally mobile tourists that are promoted and experienced as places of stillness and respite from a busy mobile world. This sense of respite is, itself, a product of the repetitive mobilities of the bodies of workers in the inns. Selby, Dixon, and Hapke (2001) account for the labour practices in an Eastern Carolina crab picking business with reference to the replacement of a largely white female workforce with Mexican women brought in on the H2-B (temporary worker) visa scheme. The labour of both white and Mexican women in the picking and 
processing of crabs is contrasted with the men who do the more romanticised but still difficult work of fishing out on the boats. The women are relatively immobilised and constrained in the space and time of their labour.

Writing on labouring bodies often references the role of affect and emotion in the experience of work-related micro-movements. Sun (2010), for instance, focuses on the poetry of dagong workers in China. Dagong workers are the internal migrants (numbering 150-200 million) who perform the labour necessary to fuel China's booming economy. Dagong means "working for the boss" and describes a new kind of class position based on migration and capitalist arrangements of power. Sun examines a burgeoning genre of dagong poetry that both represents the bodily mobilities of clocking in and out and working all day on an assembly line and the feeling of displaced homesickness for the north of China. The poetry of labour connects the fact of displacement as a migrant to the pains of the fleshy working body, locating the power relations of mobility in corporeal experience. The affective side of translocal labour mobilities is also at the heart of McKay's (2007) analysis of remittances made by Filipino domestic workers in Hong Kong. McKay refers to the "emotional labour"-the work people do on the job to manage and regulate feelings and expressions-that accompanies "productive labour" in the lives of these migrant workers (after Hochschild, 2000). Once again, the macro scale of the transnational and translocal is connected to the intimate scale of the body through the prism of "emotions."

\subsection{Life course dynamics of work and mobility}

We turn now to the "life course," which expands our focus out to other relational scales of time, biography, and kinship in the consideration of work-related mobilities. The life course approach emphasises individuals' transitions -including entry into, experiences of, and exits from work-in relation to temporal shifts in families, institutions, and societies. Katz and Monk's 1993 edited volume Full Circles: Geographies of Women over the Life Course, which included entries on mobility and work, helped to stimulate attention to the life course approach in geography. Christensen's chapter, for example, explored how women's motivations to switch from commuting to home-based work in American suburbs varied in part according to the ages of both mothers and children (Christensen, 1993).

A mobility lens on work and the life course has shifted attention toward the interactive effects and meanings among many moving parts and people, including within households. A recent study conceptualises "relational mobilities" to analyse the emergence of separate yet interdependent mobility schedules as part of life course shifts in Copenhagen families (Jensen, Sheller, \& Wind, 2015). Paying attention to transportation modes, timing, and routes of individuals in the same households illuminates "strategies of synchronizing" such as traveling together in the morning to employment and school (p. 377) that may at the same time entail conflicting affective experiences among different members of the family. The challenges of synchronisation change as children grow older or as parents "change jobs, work schedules, household location, or even partners" (p. 378). Eyer and Ferreira (2015) also look at coordinated travel, finding that Amsterdam women with young children are just as likely as other women to commute by bicycle with their offspring and generally experience this form of co-mobility as "pleasant and natural" (p. 704).

Research attending to age-related differences and shifts over the life course provides another angle of comparison on who is relatively $\mathrm{im} / \mathrm{mobile}$ with respect to work, and why and how individuals may exert and experience degrees of agency even within difficult constraints. An example of the latter would be Adivasi (tribal) children and adolescents who migrate seasonally to pollinate cotton in Gujarat, India; in contrast to what outsiders might perceive, they describe experiencing freedom as well as pride in their mobility (McKinney, 2015, p. 225).

Sociologists deploying a mobility lens have enriched understanding of employment dynamics across the life course. A team comparing "work-related forms of long-distance travel" or "high mobility" over the life course in France, Germany, Spain, and Switzerland (Kaufmann \& Viry, 2015, p. 1) has identified four patterns of movement influenced by broader economic geographies: Two groups were very mobile in their twenties and early thirties, with some in the first group returning to high mobility in their mid-forties; a third group practiced "long-term mobility" with lengthy or recurring periods; and a fourth commuted long distances daily for many years (Viry \& Vincent-Geslin, 2015, pp. 85, 92). This comparative investigation further found that, despite the normalisation of high mobility in some 
contexts, its frequent association with historical necessity and economic crises in turn tends to socialise generational cohorts in differing ways (Vincent-Geslin \& Ravalet, 2015, pp. 63-67, 79-81). Individuals' reactions to their own contemporary movements related to employment are strongly influenced not only by whether they feel that these are necessary or desired but also by their experiences of job-related mobilities earlier in their life courses-both their own and those of others such as their parents. Such experiential dynamics across a lifetime are also, as these researchers show, a matter of the changing political and economic structures shaping mobility.

\subsection{Co-mobilities and assemblages of work}

The new mobilities paradigm asks us to consider how different mobilities (of people but also of things and ideas) exist side by side with each other and with forms of immobility. This has informed our understanding of the nexus of mobility and work. Workers move as assemblages of bodies, ideas and things, although not necessarily in even or equal temporal and spatial flows. In this section, we explore how such co-mobilities become key ingredients in the production of new, localised contexts for the production of future forms of mobility. Agrawal, Cockburn, and McHale (2006), for instance, argue that flows of knowledge, and particularly of inventions, are facilitated by personal relationships and embodied labour mobility. Similarly, it is argued, when bearers of knowledge leave a particular place, there is a concurrent loss to that place as the knowledge leaves with the workers, although later research shows that a firm that loses an inventor may benefit from new networks opened up through the "diaspora" of knowledge (Oettl \& Agrawal, 2008). Finally, the places to which workers move may benefit from the networks that are formed by the mobility of knowledge bearers.

Multi-national businesses increasingly require the co-mobility of people and ideas. Tamásy, Stringer, and Le Heron (2008) have shown how the giant multi-national dairy corporation Fonterra, a company headquartered in Auckland, New Zealand, depends upon the physical mobility of its workers to transmit forms of tacit knowledge that cannot be transmitted through communication technology, confirming Urry's (2007) observation that forms of disembodied communication more often increase (rather than replace) the need for "face time" and are thus part of the global production of embodied mobilities.

A focus on the necessary mobility of workers-such as mid-level technocrats-is a feature of Larner and Laurie's (2010) work on the international spread of processes of privatisation in the water and telecommunication industries. They show how the global privatization agenda of the 1980s and 1990s rested on the embodied mobilities of key workers who carried the processes of privatisation with them. Prince (2014) examines the way in which "creativity" has been instrumentalised and transformed into policies that are packaged as "ready-made solutions to economic and social woes" (p. 91). As with processes of privatisation, these policies are carried by a network of mobile nonstate actors who travel in planes, inhabit hotel rooms, and gather at workshops and conferences. These mobile workers are key parts of a "global assemblage" that facilitates the movement of policies across heterogeneous surfaces in ways that reinforce rationalised, universal relevance.

Modes and infrastructures of transportation also move around the world through the embodied actions of workers. Bus rapid transit as a form of urban mobility has its origins in Columbia and Brazil but has traveled the globe so rapidly that it is now in over 200 cities, facilitated by what Astrid Wood (2014) calls "policy tourism": the organised visits of transport planners to sites such as Curitiba and Bogota. The bodies of experts travelling from around the world to Curitiba are thus a necessary part of future bodies travelling on express buses in separate lanes as they move to and from work in Hartford, Connecticut and hundreds of other cities across the world. The co-mobility of workers, knowledge, and things is not limited to relatively elite forms of mobility. Bedi (2015) explores the worlds of taxi drivers in Mumbai who were asked to mimic the aesthetics and organisation of Singapore's taxi fleet as disseminated by transport planners and their accompanying mobility imaginaries between Asian cities. In this case, the assemblage of moving people and imaginaries failed to take hold in the working lives of Mumbai taxi drivers thanks to the various forms of friction that often emerge as seemingly global and footloose mobilities touch down on radically different everyday worlds of work. In all of these cases and with varying degrees of success, the co-mobilities of work and 
workers play a key role in the diffusion and production of spatio-temporal contexts within which future forms of labour take place. Once again, mobilities at different scales are co-constituted.

\section{3 | CONCLUSION: THE POLITICS OF RE-WORKING MOBILITIES}

With the idea of re-working mobilities, we seek to capture the vibrancies of the new mobilities paradigm and of a critical mobilities lens in particular for the study of work, labour, and employment. The five arenas of literature reviewed above, when considered separately but also, importantly, together, might even suggest a research agenda for geographies of work. This agenda starts with the assertion that multiple scales and types of mobility are core to the socio-spatial meanings, practices, and politics of work. It thereby opens out the dynamic relations of work to other sites of lived experience and to larger mutually constituting processes and contexts. Such a "critical phenomenology" demands our attention to various forms of agency and domination as they play out in work-related mobilities, especially through power-geometries (Massey, 1993) of class, race, gender, dis/ability, and age as inherently a part of $\mathrm{im} / \mathrm{mobility}$. In short, a mobility lens brings a crucial sociality to the geography of work that keeps pace with complex changes in the worlds of labour and employment - and always with an eye to the politics of those changes. One of the most significant changes is, in fact, the destabilising and recoding of work relations by various mobilities of people, things, and ideas (D'Andrea, Ciolfi, \& Gray, 2011, p. 150; Hislop \& Axtell, 2007).

We would be remiss not to briefly consider methods. The methodological insights and innovations found in recent work-and-mobility research echo those in the mobilities literature more generally (Büscher, Urry, \& Witchger, 2010; see, for example, Fincham, McGuinness, \& Murray, 2009; for a cautionary tale, see Merriman, 2014). In the literature reviewed here, we encounter methods that "follow" the movements of workers (and/or the things with which they are co-mobile) using human or technological means, multi-method case studies that trace the assemblages of mobilities and temporalities that mark one place or moment of work, and longitudinal or comparative studies of differentiated experiences of employment-related mobility. Sites and multi-sites of examination range from the lobby of an inn or the home of a fisher to the global recruitment practices of the hotel industry or the translocal policy tourism of transportation consultants. But what we find most generative is that studies of employment-related geographical mobility seem particularly adept at fulfilling a recent call for "methods and analyses that can integrate macro and micro components, rather than allowing these to continue developing separately" (D'Andrea et al., 2011, p. 156; see also Büscher et al., 2010).

A key part of re-working mobilities is thus the further development of modes of research that can stand up to the complexities of mobility as both lived and structured and as both fluid and predictable. Such a "critical reorientation," observe D'Andrea et al. (2011) "will also enhance the interventional and social capabilities of mobilities research" (p. 157). Indeed, we close by suggesting that because work is a core human activity increasingly steeped in multiple mobilities and integrally connected to the sites and rhythms of a host of social domains-from families and homes to built and symbolic infrastructures-it stimulates the "strategic diversity" (Faulconbridge \& Hui, 2016, p. 1) of the NMP as a conceptual field and attunes it to lived worlds of power and possibility. As we have seen, emergent literature on work-and-mobility expands ways of asking and knowing already established in the critical and feminist theorising of work, space, and time (Roseman et al., 2015) as political phenomena. The mobilities approach opens up new questions about work and employment and, in the process, is re-animated as a critical intervention for "re-working" geography.

\section{ORCID}

Sara Dorow 니 http://orcid.org/0000-0002-7698-6860

\section{REFERENCES}

Ackers, L. (2005). Scientific migration within the EU: Introduction to the special issue. Innovations, 18, 275-276. 
Adey, P. (2010). Mobility. London: Routledge.

Adey, P., Bissell, D., Hannam, K., Merriman, P., \& Sheller, M. (2014). The Routledge handbook of mobilities. London: Routledge.

Agrawal, A., Cockburn, I., \& McHale, J. (2006). Gone but not forgotten: Knowledge flows, labor mobility, and enduring social relationships. Journal of Economic Geography, 6, 571-591.

Akyelken, N. (2013). Development and gendered mobilities: Narratives from the women of Mardin, Turkey. Mobilities, 8(3), 424-439.

Batnitzky, A., McDowell, L., \& Dyer, S. (2008). A middle-class global mobility? The working lives of Indian men in a West London hotel. Global Networks, 8(1), 51-70.

Beck, S. (2007). Meeting on the margins: Cantonese 'old-timers' and Fujianese 'newcomers'. Population, Space and Place, 13(2), 141-152.

Bedi, T. (2015). Mimicry, friction and trans-urban imaginaries: Mumbai taxis/Singapore-style. Environment and Planning A. doi: $0308518 \times 15594803$

Bissell, D. (2016). Micropolitics of mobility: Public transport commuting and everyday encounters with forces of enablement and constraint. Annals of the American Association of Geographers, 106, 394-403.

Blunt, A. (2007). Cultural geographies of migration: Mobility, transnationality and diaspora. Progress in Human Geography, 31 , 684-694.

Büscher, M., Urry, J., \& Witchger, K. (Eds) (2010). Mobile methods. Routledge.

Christensen, K. (1993). Eliminating the journey to work: Home-based work across the life course of women. In C. Katz, \& J. Monk (Eds.), Full circles-Geographies of women over the life course (pp. 55-87). London: Routledge.

Cohen, R. L. (2010). Rethinking 'mobile work': Boundaries of space, time and social relation in the working lives of mobile hairstylists. Work, Employment \& Society, 24(1), 65-84.

Crang, M. (2001). Temporalised space and motion. In J. May, \& N. Thrift (Eds.), Timespace: Geographies of temporality (pp. 187-207). London: Routledge.

Cresswell, T. (2006). On the move: Mobility in the modern Western world. Taylor \& Francis.

Cresswell, T. (2010). Towards a politics of mobility. Environment and Planning D: Society and Space, 28, 17-31.

Cresswell, T., Dorow, S., \& Roseman, S. (2016). Putting mobility theory to work: Conceptualizing employment-related geographical mobility. Environment and Planning A. doi: 0308518X16649184

D'Andrea, A., Ciolfi, L., \& Gray, B. (2011). Methodological challenges and innovations in mobilities research. Mobilities, 6(2), 149-160.

Datta, K., Mcllwaine, D., Herbert, J., Evans, Y., May, J., \& Wills, J. (2008). Mobile masculinities: Men, migration and low paid work in London. London: Department of Geography Queen Mary, University of London.

Desjarlais, R. (2005). Movement, stillness: On the sensory world of a shelter for the 'homeless mentally ill. In D. Howes (Ed.), Empire of the senses: The sensual culture reader (pp. 369-379). Oxford: Berg.

Dyer, S., McDowell, L., \& Batnitzky, A. (2010). The impact of migration on the gendering of service work: The case of a West London hotel. Gender, Work \& Organization, 17, 635-657.

Edensor, T. (2011). Commuter: Mobility, rhythm and commuting. In T. Cresswell, \& P. Merriman (Eds.), Geographies of mobilities: Practices, spaces, subjects (pp. 189-204). Farnham: Ashgate.

Eyer, A., \& Ferreira, A. (2015). Taking the tyke on a bike: Mothers' and childless women's space-time geographies in Amsterdam compared. Environment and Planning A, 47, 691-708.

Faulconbridge, J., \& Hui, A. (2016). Traces of a mobile field: Ten years of mobilities research. Mobilities, 11(1), 1-14.

Fincham, B., McGuinness, M., \& Murray, L. (Eds) (2009). Mobile methodologies. Springer.

Gerrard, S. (2013). Mobilities, materialities, and masculinities: Interconnected mobility practices in Norwegian coastal fisheries. Norsk Geografisk Tidsskrift-Norwegian Journal of Geography, 67(5), 312-319.

Gilbert, M. R. (1998). "Race," space, and power: The survival strategies of working poor women. Annals of the Association of American Geographers, 88, 595-621.

Green, N. (2002). On the move: Technology, mobility, and the mediation of social time and space. The Information Society, 18(4), 281-292.

Hannam, K., Sheller, M., \& Urry, J. (2006). Editorial: Mobilities, immobilities and moorings. Mobilities, 1, 1-22.

Hanson, S. (2005). Perspectives on the geographic stability and mobility of people in cities. Proceedings of the National Academy of Sciences, 102, 15301-15306.

Hanson, S. (2010). Gender and mobility: New approaches for informing sustainability. Gender, Place, and Culture, 17(1), 5-23. 
Hanson, S., \& Pratt, G. (1995). Gender, work, and space. London and New York: Routledge.

Herod, A. (1997). From a geography of labor to a labor geography: Labor's spatial fix and the geography of capitalism. Antipode, 29(1), 1-31.

Hinrichs, K., Roche, W., \& Sirianni, C. (1991). From standardization to flexibility: Changes in the political economy of working time. In K. Hinrichs, W. Roche, \& C. Sirianni (Eds.), Working time in transition: The political economy of working hours in industrial nations (pp. 3-25). Philadelphia: Temple University Press.

Hislop, D., \& Axtell, C. (2007). The neglect of spatial mobility in contemporary studies of work: The case of telework. New Technology, Work and Employment, 22(1), 34-51.

Hochschild, A. R. (2000). Global care chains and emotional surplus value. In W. Hutton, \& A. Giddens (Eds.), On the edge: Living with global capitalism (pp. 130-146). London: Jonathan Cape.

Hui, A. (2016). The boundaries of interdisciplinary fields: Temporalities shaping the past and future of dialogue between migration and mobilities research. Mobilities, 11(1), 6-82.

Hyndman, J. (2004). The (geo) politics of mobility. In L. A. Staeheli, E. Kofman, \& L. J. Peake (Eds.), Mapping women, making politics: Feminist perspectives on political geography (pp. 169-184). New York and London: Routledge.

Jeanes, E., Loacker, B., Śliwa, M., \& Weiskopf, R. (2015). Mobilities in contemporary worlds of work and organizing. Ephemera: Theory and Politics in Organization, 15, 705-723.

Jensen, O. B., Sheller, M., \& Wind, S. (2015). Together and apart: Affective ambiences and negotiation in families' everyday life and mobility. Mobilities, 10(3), 363-382.

Kanngieser, A. (2013). Tracking and tracing: Geographies of logistical governance and labouring bodies. Environment and Planning D: Society and Space, 31, 594-610.

Kaufmann, V., Bergman, M. M., \& Joye, D. (2004). Motility: Mobility as capital. International Journal of Urban and Regional Research, 28, 745-756.

Kaufmann, V., \& Viry, G. (2015). High mobility as social phenomenon. In G. Viry, \& V. Kaufmann (Eds.), High mobility in Europe: Work and personal life (pp. 1-15)Palgrave Macmillan UK.

Kelly, P. F. (2012). Labor, movement: Migration, mobility, and geographies of work. In T. J. Barnes, J. Peck, \& E. Sheppard (Eds.), The Wiley-Blackwell companion to economic geography (Vol. 21) (pp. 431-443). West Sussex: John Wiley \& Sons.

Larner, W., \& Laurie, N. (2010). Travelling technocrats, embodied knowledges: Globalising privatisation in telecoms and water. Geoforum, 41, 218-226.

Law, R. (1999). Beyond 'women and transport': Towards new geographies of gender and daily mobility. Progress in Human Geography, 23, 567-588.

Ley, D. (2011). Mobility-Part I. In J. A. Agnew, \& J. S. Duncan (Eds.), The Wiley-Blackwell companion to human geography (Vol. 16) (pp. 361-372). West Sussex, UK: John Wiley \& Sons. 373-386

Lin, W. (2015). 'Cabin pressure': Designing affective atmospheres in airline travel. Transactions of the Institute of British Geographers, 40, 287-299.

Massey, D. (1993). Power-geometry and a progressive sense of place. In J. Bird, B. Curits, T. Utnam, G. Robertson, \& L. Tickner (Eds.), Mapping the futures: Local cultures, global change (pp. 59-68). London and New York: Routledge.

Massey, D. (1994). Space, place and gender. Oxford: Polity Press.

McDowell, L. (2009). Working bodies. Interactive service employment and workplace identities. Malden/Oxfort: Blackwell.

McKay, D. (2007). 'Sending dollars shows feeling'-Emotions and economies in Filipino migration. Mobilities, 2(2), $175-194$.

McKinney, K. (2015). Situating corporate framings of child labor: Toward grounded geographies of working children in globalized agriculture. Geoforum, 59, 219-227.

McMorran, C. (2015). Mobilities amid the production of fixities: Labor in a Japanese inn. Mobilities, 10(1), 83-99.

Merriman, P. (2014). Rethinking mobile methods. Mobilities, 9(2), 167-187.

Mitchell, D. (2012). They saved the crops: Labor, landscape, and the struggle over industrial farming in Bracero-era California (Geographies of Justice and Social Transformation, number 10). Athens: University of Georgia Press.

Nóvoa, A. (2014). 'A country on wheels': A mobile ethnography of Portuguese lorry drivers. Environment and Planning A, 46, 2834-2847.

Oettl, A., \& Agrawal, A. (2008). International labor mobility and knowledge flow externalities. Journal of International Business Studies, 39, 1242-1260.

Omi, M., \& Winant, H. (1994). Racial formation in the United States: From the 1960s to the 1990s. London and New York: Routledge. 
Parks, V. (2016). Rosa Parks redux: Racial mobility projects on the journey to work. Annals of the American Association of Geographers, 106(2), 292-299.

Prince, R. (2014). Consultants and the global assemblage of culture and creativity. Transactions of the Institute of British Geographers, 39(1), 90-101.

Revill, G. (2011). Mobility-Part II. In J. A. Agnew, \& J. S. Duncan (Eds.), The Wiley-Blackwell companion to human geography (Vol. 16) (pp. 373-386). West Sussex, UK: John Wiley \& Sons. 373-386

Ritterbusch, A. E. (2016). Mobilities at gunpoint: The geographies of (im) mobility of transgender sex workers in Colombia. Annals of the American Association of Geographers, 106(2), 422-433.

Roseman, S. R., Barber, P. G., \& Neis, B. (2015). Towards a feminist political economy framework for analyzing employmentrelated geographical mobility. Studies in Political Economy, 95(1), 175-203.

Salazar, N. B., \& Jayaram, K. (Eds) (2016). Keywords of mobility: Critical engagements. Berghahn.

Selby, E. F., Dixon, D. P., \& Hapke, H. M. (2001). A woman's place in the crab processing industry of Eastern Carolina. Gender, Place and Culture: A Journal of Feminist Geography, 8(3), 229-253.

Sheller, M., \& Urry, J. (2006). The new mobilities paradigm. Environment and Planning A, 38(2), 207-226.

Silva, J. M., \& Ornat, M. J. (2015). Intersectionality and transnational mobility between Brazil and Spain in travesti prostitution networks. Gender, Place \& Culture, 22, 1073-1088.

Sun, W. (2010). Narrating translocality: Dagong poetry and the subaltern imagination. Mobilities, 5(3), 291-309.

Tamásy, C., Stringer, C., \& Le Heron, R. (2008). Knowledge transfer in a globalising world economy: Fonterra's management of its mobile work force. Geographische Zeitschrift, 140-157.

Urry, J. (2007). Mobilities. Polity.

van Blerk, L. (2016). Livelihoods as relational im/mobilities: Exploring the everyday practices of young female sex workers in Ethiopia. Annals of the American Association of Geographers, 106(2), 413-421.

Verne, J. (2012). Living translocally: Space, culture and economy in contemporary Swahili trade. Stuttgart, Germany: Franz Steiner Verlag.

Vincent-Geslin, S., \& Ravalet, E. (2015). Socialisation to high mobility? In G. Viry, \& V. Kaufmann (Eds.), High mobility in Europe: Work and personal life (pp. 59-82). Palgrave Macmillan UK.

Viry, G., \& Vincent-Geslin, S. (2015). High mobility over the life course. In G. Viry, \& V. Kaufmann (Eds.), High mobility in Europe: Work and personal life (pp. 83-100). Palgrave Macmillan UK.

Waite, L. (2009). A place and space for a critical geography of precarity? Geography Compass, 3(1), 412-433.

Walsh, K. (2011). Migrant masculinities and domestic space: British home-making practices in Dubai. Transactions of the Institute of British Geographers, 36, 516-529.

Weeks, K. (2007). Life within and against work: Affective labor, feminist critique, and post-Fordist politics. Ephemera, 7(1), 233-249.

Whitelegg, D. (2007). Working the skies: The fast-paced, disorienting world of the flight attendant. NYU Press.

Wood, A. (2014). Learning through policy tourism: Circulating bus rapid transit from South America to South Africa. Environment and Planning A, 46, 2654-2669.

Yeoh, B. S., \& Ramdas, K. (2014). Gender, migration, mobility and transnationalism. Gender, Place \& Culture, 21, 1197-1213.

Sara Dorow is Associate Professor and Chair of the Department of Sociology at the University of Alberta in Edmonton, Alberta, Canada. She is author of Transnational Adoption: A Cultural Economy of Race, Gender, and Kinship (NYU Press, 2006) and of numerous articles and reports on transnationalism, mobility and migration, and intersectional studies of gender, family, racialisation, and care work. Currently, she is Alberta Team Lead for the international research project "On the Move: Employment-Related Geographical Mobility in the Canadian Context", and is writing a book on mobility and community in the oil sands of northeast Alberta.

Sharon Roseman is Professor of Anthropology and Associate Dean (Research and Graduate Programs) in the Faculty of Humanities and Social Sciences at Memorial University. She has focused on historical and ethnographic approaches to mobility, examining transportation labour, commuting, pedestrian activism, migration, tourism, and pilgrimage. Her current project focuses on ferry commuting and ferry employment in Newfoundland and 
Labrador. She is author or editor of five books, including The Tourism Imaginary and Pilgrimages to the Edges of the World (Channel View, 2015) and Recasting Culture and Space in Iberian Contexts (SUNY Press, 2008). She recently completed a film with Elizabeth Yeoman entitled Honk If You Want Me Off the Road.

Tim Cresswell is Professor of American Studies, Dean of the Faculty, and Vice President for Academic Affairs at Trinity College, Hartford, Connecticut, USA. A cultural geographer by training, he is the author or editor of nine books on the role of space, place, and mobility in social and cultural life. These include Place: An Introduction (Blackwell, 2014) and On the Move: Mobility in the Modern Western World (Routledge, 2006). He is also a poet and author of two collections of poetry-most recently Fence (Penned in the Margins, 2015). He is an inaugural editor of the AAG journal GeoHumanities.

How to cite this article: Dorow S, Roseman SR, Cresswell T. Re-working mobilities: Emergent geographies of employment-related mobility. Geography Compass. 2017;11:e12350. https://doi.org/10.1111/gec3.12350 